\title{
Carbon fluxes in coral reefs. I. Lagrangian measurement of community metabolism and resulting air-sea $\mathrm{CO}_{2}$ disequilibrium
}

\author{
J.-P. Gattuso ${ }^{1,2, *}$, M. Pichon ${ }^{2,3,4}$, B. Delesalle ${ }^{2,4}$, C. Canon ${ }^{5, * *}$, M. Frankignoulle ${ }^{5, * *}$ \\ 'Observatoire Océanologique Européen, Centre Scientifique de Monaco, Avenue Saint-Martin, MC-98000 Monaco, \\ Principality of Monaco \\ ${ }^{2}$ Laboratoire de Biologie Marine et Malacologie, URA CNRS 1453, EPHE, Université de Perpignan, \\ F-66860 Perpignan Cedex, France \\ ${ }^{3}$ Australian Institute of Marine Science, PMB No. 3, Townsville M. C., Queensland 4810, Australia \\ ${ }^{4}$ Centre de Recherches Insulaires et Observatoire de l'Environnement, EPHE, BP 1013, Moorea, French Polynesia \\ ${ }^{5}$ Laboratoire d'Océanologie, Université de Liège, Institut de Chimie Bât B6, B-4000 Sart Tilman, Belgium
}

\begin{abstract}
Community metabolism was investigated using a Lagrangian flow respirometry technique on 2 reef flats at Moorea (French l'olynesia) during austral winter and Yonge Reef (Great Barrier Reef) during austral summer. The data were used to estimate related air-sea $\mathrm{CO}_{2}$ disequilibrium. A sine function did not satisfactorily model the diel light curves and overestimated the metabolic parameters. The ranges of community gross primary production and respiration $\left(P_{4}\right.$ and $R ; 9$ to $\left.15 \mathrm{~g} \mathrm{C} \mathrm{m}^{-2} \mathrm{~d}^{-1}\right)$ were within the range previously reported for reef flats, and community net calcification $\left(G_{i} 19\right.$ to $25 \mathrm{~g}$ $\mathrm{CaCO}_{3} \mathrm{~m}^{-2} \mathrm{~d}^{-1}$ ) was higher than the 'standard' range. The molar ratio of organic to inorganc carbon uptake was 6:1 for both sites. The reef flat at Moorea displayed a hugher rate of organic production and a lower rate of calcification compared to prevous measurements carried out during austral summer. The approximate uncertainty of the daily metabolic parameters was estimated using a procedure based on a Monte Carlo simulation. The standard errors of $P_{\mathrm{g}} R$ and $P_{\mathrm{g}} / R$ expressed as a percentage of the mean are lower than $3 \%$ but are comparatively larger for $E$, the excess production $(6$ to $78 \%)$. The daily air-sea $\mathrm{CO}_{2}$ flux $\left(\mathrm{FCO}_{2}\right)$ was positive throughout the field experiments, indicating that the reef flats at Moorea and Yonge Reef released $\mathrm{CO}_{2}$ to the atmosphere at the time of measurement. $F_{\mathrm{CO}_{2}}$ decreased as a function of increasing daily irradiance.
\end{abstract}

KEY WORDS: Coral reefs Primary production - Respiration C Calcification - Air-sea $\mathrm{CO}_{2}$ flux $\cdot$ Light

\section{INTRODUCTION}

The biological processes controlling the $\mathrm{CO}_{2}$ partial pressure in seawater $\left(\mathrm{pCO}_{2}\right)$ and, consequently, the air-sea $\mathrm{CO}_{2}$ fluxes are net organic production and calcification, which have opposite effects on $\mathrm{pCO}_{2}$. Coccolithophorid blooms and coral reefs are the major marine photosynthetic and calcifying systems and are, therefore, well suited to studies of the interactive

•E-mail gattuso@naxos.unice.fr

- Present address: Université de Liège, Mécanique des Fluides Géophysiques, Unité d'Océanographie Chimique, Institut de Physique (B5), B-4000 Sart Tilman, Belgıum effects of photosynthesis-respiration and precipitation-dissolution of calcium carbonate on the seawater $\mathrm{CO}_{2}$ system and air-sea $\mathrm{CO}_{2}$ fluxes. Coccolithophorid blooms are transient (Holligan et al. 1993), annually cover on average $14 \times 10^{5} \mathrm{~km}^{2}$ of the world's oceans (Brown \& Yoder 1994) and have been shown to behave as sources for atmospheric $\mathrm{CO}_{2}$ (Robertson et al. 1994). Coral reefs are permanent, long-lived ecosystems covering $6 \times 10^{5} \mathrm{~km}^{2}$ (Smith 1978a). There is a rather large set of data on reef community metabolism (Kinsey 1985. Smith 1995) but very few estimates of air-sea $\mathrm{CO}_{2}$ fluxes in coral reefs (Gattuso et al. 1993). In most reefs investigated, gross primary production $\left(P_{g}\right)$ and respiration $(R)$ are nearly balanced $\left(P_{\mathrm{g}} / R=1\right)$ and net 
community production is close to 0 . Net calcification $(G)$ is, therefore, the main process affecting the seawater $\mathrm{CO}_{2}$ system.

Ware et al. (1992) provided numerical evidence on the effect of calcification on the seawater inorganic carbon system and suggested that coral reefs are slight sources of $\mathrm{CO}_{2}$ to the atmosphere. Smith (1995) proposed that the net air-sea transfer of $\mathrm{CO}_{2}$ in complete reef systems is less than \pm 4 to $5 \mathrm{~mol} \mathrm{~m}-\mathrm{yr}^{-1}$ Gattuso et al. (1995) described a model which enables the estimation of the effect of photosynthetic and calcifying systems of air-sea $\mathrm{CO}_{2}$ fluxes from average values of $P_{0 \mathrm{y}} R$ and $G$. They predicted that 'standard' reef flats and complete reef systems can be expected to cause $\mathrm{CO}_{2}$ evasion to the atmosphere. The significance of this prediction for complete reef systems is unclear due the lack of confidence intervals for $P_{\mathrm{g}}, R$ and $G$ (Gattuso et al. 1995). Information on the variability of daily metabolic parameters is critical, for example, to compare metabolic performances between reefs, but is also missing for individual sites due to the lack of an appropriate technique to estimate them. The prediction that reef flats release $\mathrm{CO}_{2}$ to the atmosphere seems robust and is confirmed by the only existing data on air-sea $\mathrm{CO}_{2}$ flux which showed that a barrier reef flat at Moorea (French Polynesia) was a slight source of $\mathrm{CO}_{2}$ during austral summer 1991 (Gattuso et al. 1993).

Several recent studies suggest, however, that reefs may be sinks for atmospheric $\mathrm{CO}_{2}$ due to a high net primary production (Kayanne et al. 1995, Yamamuro et al. 1995, Kraines et al. in press) While concerns have been expressed about the techniques used in some of these studies, including the limited data set and the representativity of the study sites (Smith 1995, Gattuso et al. 1996), as well as about the long-term inconsistency of this suggestion (Buddemeier 1996), it is not surprising that some individual reefs or some of their components (see Hatcher 1988) depart from the general trend (low net primary production).

Previous measurements of community metabolism and air-sea $\mathrm{CO}_{2}$ flux (Gattuso et al. 1993) were carried out during a single season (austral summer) in a single locality (Tiahura Barrier Reef, Moorea) There is clearly a need to complement these data both on temporal and spatial scales. Indeed, the seasonal pattern of reef metabolism in French Polynesia (Payri 1987) and elsewhere (see Kinsey 1985) is reported to be very strong and may result in important changes in the cycling of carbon. Additionally, the Tiahura reef system is subject to a relatively intense human impact (Wolanski et al. 1993) which may lead to an increase in community net production and a decrease in net calcification compared with more pristine reefs (Kinsey 1988).

The aim of the present study is to investigate (1) the effect of reef metabolism on the inorganic carbon system during summer and winter at Moorea, (2) sitespecific differences by comparing the metabolic performances at Moorea and Yonge Reef (Great Barrier Reef, subject to little human impact) and (3) the air-sea $\mathrm{CO}_{2}$ disequilibrium resulting from reef metabolism. We also attempted to derive a procedure enabling estimation of the robustness of the daily metabolic parameters derived from Lagrangian measurements of community production, respiration and calcification. The present paper focuses on community metabolism issues (Lagrangian approach) while the dynamics of the inorganic carbon system (Eulerian approach) is presented in a companion paper (Frankignoulle et al. 1996 in this issue)

\section{MATERIAL AND METHODS}

Geographical framework. The reef at Moorea $117^{\circ}$ $29^{\prime} \mathrm{S}, 149^{\circ} 54^{\prime} \mathrm{W}$ ) formed around a volcanic island (Fig 1A). The reef is comparatively narrow at the study site and oceanic water flows across it to a drainage channel. It is exposed to typically oceanic waters on its seaward side and its landward fringe is affected by terrigenous influence and anthropogenic pressure due to the proximity of the island (Wolanski et al. 1993). The tidal range is $\leq 0.5 \mathrm{~m}$ and the annual variation of the sea surface temperature is $\leq 7^{\circ} \mathrm{C}$ (Galzin \& Pointier 1985)

Yonge Reef $\left(14^{\circ} 35^{\prime} \mathrm{S}, 145^{\circ} 37^{\prime} \mathrm{E}\right)$, in the northern half of the Great Barrier Reef (GBR), grows on the margin of the continental shelf (Fig 1B) It is a barrier reef with the typical 'ribbon' morphology of shelf edge coral reefs and has a well developed reef flat. It is separated and isolated from the Australian continental landmass by the GBR lagoon, which in that area is $-50 \mathrm{~km}$ wide. The tidal range is $\leq 3 \mathrm{~m}$ and the annual variation of the sea surface temperature is $\leq 6^{\circ} \mathrm{C}$ ( $\mathrm{M}$. Pichon unpubl. obs.).

Community composition. Quantitative information on the structure and zonation of benthic reef communities were obtained by the use of the line transect method (e.g. Loya 1972, Pichon \& Morrissey 1981) Lines parallel to the reef front were surveyed for coral species composition and cover (Yonge Reef), and for corals and other benthic components (turf, fleshy and coralline algae, rubble and sediment) at Moorea Length of individual line transects was $30 \mathrm{~m}$ at Yonge Reef and $50 \mathrm{~m}$ at Moorea.

Community productivity and calcification. Field experiments: Community metabolism was measured in flowing water (Marsh \& Smith 1978, Smith 1978b) using a Lagrangian flow respirometry technique (Barnes 1983, Barnes \& Devereux 1984). Field experiments took place in July and August 1992 at Moorea 
Fig. 1 Locations of the study sites

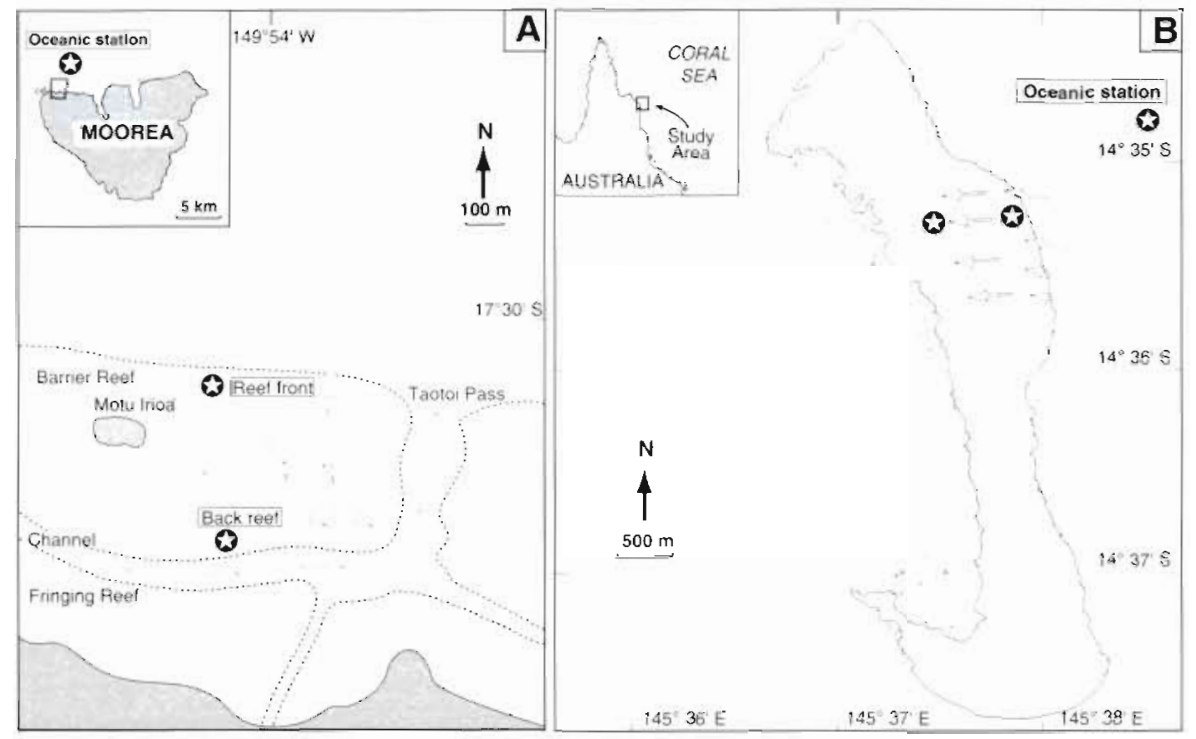

and in December 1993 at Yonge Reef. Changes in the chemistry of the water flowing from the reef front to the back reef were monitored during transect experiments by a surface-drifting instrument package (buoy). Transects ( $\mathrm{n}=12$ at Moorea and $\mathrm{n}=15$ at Yonge Reef) were carried out under a wide range of average irradiance in air 10 to $1900 \mu \mathrm{mol}$ photons $\mathrm{m}^{-2}$ $\mathrm{s}^{-1}$ ). Both the oxygen and $\mathrm{CO}_{2}$ techniques were used (Marsh \& Smith 1978) The buoy carried 4 sensors: a galvanic oxygen sensor (Kent), a pH electrode (Radiometer, GK 2401C), a thermistor (Analog Devices, AC $2626 \mathrm{~K} 4$ ) and a quantum light sensor ( $\mathrm{Li}$ Cor, LI-192SA). The pH electrode was pressure-compensated (see Chisholm et al. 1990). Sensors were interrogated every second and average data were stored every $10 \mathrm{~s}$ during the transects. The buoy was tracked down every minute from the upstream station. Duplicate seawater samples were taken at the beginning and end of each transect for later determination of total alkalinity. Incident irradiance was measured onshore (Moorea) or on a mast at the back reef site (Yonge Reef) throughout the field experiments using an LI-192SA quantum sensor, averaged and logged every minute on an LI-1000 datalogger.

Calibration of sensors: The oxygen sensor and $\mathrm{pH}$ electrode were calibrated daily. The oxygen sensor was calibrated against air-saturated seawater and a saturated solution of sodium dithionite (zero oxygen). The pH electrode was calibrated against National Bureau of Standards (NBS) buffers: pH 6.865 and 7.413 at $37^{\circ} \mathrm{C}$ (Radiometer). Calibration had been checked against the seawater scale (SWS; Dickson 1993) on some occasions. The pH of a TRIS buffer (Bates 1982) was typically overestimated by $0.006 \mathrm{pH}$ units using the NBS scale.
Total alkalinity: Seawater for total alkalinity (TA) determination was filtered immediately after sampling on Whatman GF/C membranes and stored in BOD bottles in darkness at 4 to $10^{\circ} \mathrm{C}$ pending analysis. TA was measured as described by Gattusa et al. (1993). Accuracy against pure carbonate standard solutions was $0.1 \%\left(2 \mu \mathrm{eq} \mathrm{kg}^{-1}\right)$ and the average precision ( $2 \times$ $\mathrm{SD} /$ mean) was $0.16 \%$.

Data processing: Back in the laboratory, raw data stored in the buoy were dumped and converted to absolute $\mathrm{pH}, \mathrm{O}_{2}$, temperature and light values. Calcification and partitioning of organic and inorganic carbon metabolisms were estimated using the alkalinity anomaly technique (Smith \& Key 1975). The contribution of nutrients to changes in total alkalinity was negligible at Yonge Reef since there were no or very small changes in nutrient concentrations during the transects (data not shown). Since it is likely that a similar situation prevailed at Moorea, fluxes of total alkalinity were not corrected for changes in ions other than those of the carbonate system.

Net primary production and calcification during each transect were calculated as follows:

$$
\begin{gathered}
p_{\text {net }}\left(\mathrm{O}_{2}\right)=\frac{\Delta \mathrm{O}_{2} \rho z}{\Delta t 10^{3}}+f_{\mathrm{O}_{2}} \\
p_{\text {net }}\left(\mathrm{CO}_{2}\right)=\frac{\Delta \mathrm{DIC} \rho z}{\Delta t}-g+f_{\mathrm{CO}}, \\
g=\frac{\Delta \mathrm{TA} \rho z}{2 \Delta t}
\end{gathered}
$$

where $p_{\text {net }}$ is net primary production (in terms of $\mathrm{O}_{2}$ or $\mathrm{CO}_{2}$ ) in $\mathrm{mmol} \mathrm{m}^{-2} \mathrm{~h}^{-1}$ and $p_{\text {nei }}=r$, the community res- 
piration at night; $g$ is calcification in $\mathrm{mmol} \mathrm{CaCO}_{3} \mathrm{~m}^{2}$ $\mathrm{h}^{-1} ; \Delta \mathrm{O}_{2}$ is change in dissolved oxygen concentration ( $\mu$ mol $\mathrm{kg}^{-1}$ ) estimated by regressing $\left[\mathrm{O}_{2}\right]$ versus time; $\rho$ is seawater density in $\mathrm{kg} \mathrm{m}^{-3}$ (Millero \& Poisson 1981); $z$ is depth $(\mathrm{m}): \Delta t$ is duration of transect $(\mathrm{h}) ; f_{\mathrm{O}_{2}}$ and $f_{\mathrm{CO}_{2}}$ are air-sea $\mathrm{O}_{2}$ and $\mathrm{CO}_{2}$ fluxes ( $\mathrm{mmol} \mathrm{m} \mathrm{m}^{-2} \mathrm{~h}^{-1}$ ) during transect estimated as described by Gattuso et al. (1993); $\triangle \mathrm{DIC}$ is change in total dissolved inorganic carbon (mmol $\mathrm{kg}^{-1}$ ); and $\triangle \mathrm{TA}$ is change in total alkalinity (meq $\mathrm{kg}^{-1}$ ).

By convention, small letters refer to instantaneous and hourly fluxes $\left(f_{\mathrm{CO}_{2}}, p, r, g\right)$ while capital letters $\left(F_{\mathrm{CO}_{2}}, P_{\mathrm{g}}, R, G\right)$ refer to fluxes integrated over the day, night or $24 \mathrm{~h}$. Absolute values of $P_{\mathrm{g}} / R$ are reported throughout the paper. $p_{\text {net }}\left(\mathrm{O}_{2}\right)$ and $p_{\mathrm{n}}\left(\mathrm{CO}_{2}\right)$ were used to compute the respiratory quotient at night $[R Q=$ $\left.\left|p_{\text {met }}\left(\mathrm{CO}_{2}\right) / p_{\text {net }}\left(\mathrm{O}_{2}\right)\right|\right]$ and the net photosynthetic quotient during the day $\left[P Q_{\text {net }}=\left|p_{\text {net }}\left(\mathrm{O}_{2}\right) / p_{\text {net }}\left(\mathrm{CO}_{2}\right)\right|\right]$. The net productivity data measured around the compensation irradiance were excluded from the computation of average $P Q_{\text {net }}$. True $P Q$ was computed as described by Gattuso \& Jaubert (1988) for plant-animal symbiotic units. Calcification rates were expressed as negative values and rates of dissolution of $\mathrm{CaCO}_{3}$ as positive values.

Computation of light response curve parameters: The light response curve parameters, i.e. the productivity- and calcification-irradiance $(P-I$ and $G-I)$ curves, were calculated using 2 different approaches (Fig. 2). The first approach is similar to that used by previous investigators (e.g Barnes \& Devereux 1984, Gattuso et al. 1993). Functions were fitted to the light response curves of net primary production ( $p_{\text {net }}$ in terms of $\mathrm{O}_{2}$ and $\mathrm{CO}_{2}$ ) and calcification (g) using linear or non-linear curve fitting (JMP 3.0 for Macintosh, SAS Institute Inc., or MacCurveFit 1.1). The comparison of the parameters of the light response curves is difficult when different functions are used for different sites. However, as the overriding consideration was to get the best estimates of the daily metabolic budgets, we nevertheless decided to select the functions providing the best fits. The exponential function $\{y=a[1-$ $\exp (-x / b)]+c]$ and the hyperbolic tangent function $[y$ $=a \tanh (-X / b)+c]$ produced the best fits for $P-I$ curves of, respectively, Moorea and Yonge Reef. The G-I curves were modelled using an exponential function at Moorea and a linear function for Yonge Reef. The curve fitting procedure returns average parameters \pm asymptotic standard error (non-linear curve fitting) or \pm standard error (linear curve fitting)

In the second approach, a Monte Carlo simulation was applied to the rates of net primary production ( $p_{\text {net }}$ in terms of $\mathrm{O}_{2}$ and $\mathrm{CO}_{2}$ ) and calcification $(g)$ measured during each transect using their standard errors as derived by taking into account the errors of each

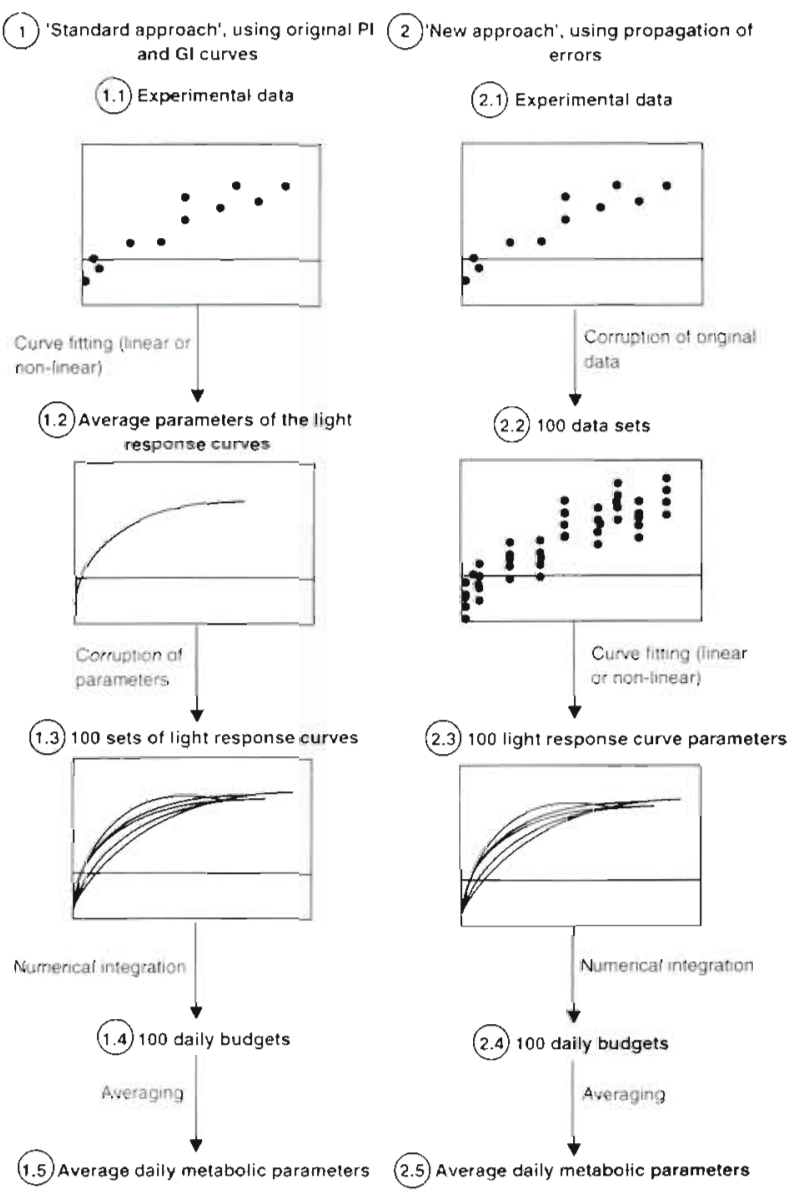

Fig. 2. Two procedures adopted in this paper to estimate the uncertainty of daily metabolic parameters

variable used to compute $p_{\text {net }}$ and $g$ (Eqs. 1 to 3 ). Standard errors were calculated using data shown in Table 1 and standard error propagation formulae given by Gans (1992). The experimental data points of the $P-I$ and $G-I$ curves were corrupted using a random number generator (Excel 5.0) in order to produce 100

Table 1. Errors used to estimate the standard errors of daily metabolic parameters. Errors are reported as a percentage of the mean ( $\mathrm{SD} / \mathrm{mean}$ ) or as an absolute value. (1) $\mathrm{\Delta O}_{2}$ was computed using the standard deviation of the regression line of oxygen concentration versus time; (2) the exact errors for $f_{\mathrm{O}_{2}}$ and $f_{\mathrm{CO}_{2}}$ are unknown and were arbitrarily set to $30 \%$

\begin{tabular}{|lcl|}
\hline Vanable & Error & Source \\
\hline $\mathrm{SO}\left(\mu \mathrm{mol} \mathrm{kg}{ }^{-1}\right)$ & $1-11 \%$ & $(1)$ \\
$\left.\mathrm{DIC}(\mu \mathrm{mol} \mathrm{kg})^{-1}\right)$ & $0.6 \%$ & Dickson \& Riley (1978) \\
$\mathrm{TA}(\mu \mathrm{eq} \mathrm{kg})$ & $0.08 \%$ & Gattuso et al. (1993) \\
Density $\left(\mathrm{kg} \mathrm{m}^{-3}\right)$ & $3.66 \times 10^{-2}$ & Millero \& Poisson (1981) \\
Depth. $(\mathrm{m})$ & 0.1 & \\
Air-sea $\mathrm{O}_{2}$ flux & $30 \%$ & $(2)$ \\
Air-sea $\mathrm{CO}_{2}$ flux & $30 \%$ & $(2)$ \\
\hline
\end{tabular}


data sets for each curve. The corrupted data sets were normally distributed with a mean equal to the experimental data point and a standard deviation calculated as described above. The curve fitting procedure was then applied to the 100 data sets, returning $100 \mathrm{P}$ - $I$ and $G-I$ curve parameters which were averaged.

Computation of daily metabolic budgets: The daily metabolic parameters, such as gross primary production $\left(P_{\mathrm{g}}\right)$, respiration $(R)$ and calcification $(G)$, were estimated by integrating the $P$ - $I$ and $G$ - $I$ curves derived from the 2 approaches described above with respect to the diurnal changes of irradiance in air. Both field and modelled diel light curves were used. The theoretical light data were obtained using a sine function (Chalker \& Dunlap 1983) based on the average times of the beginning (Moorea 06:07 h; Yonge Reef 05:10 h) and end (Moorea 18:08 h; Yonge Reef 19:10 h) of the light record. These times are close to the times of morning and afternoon civil twilights used by Chalker \& Dunlap (1983). The average maximum surface irradiance measured during the field experiments was 1795 and $2256 \mu \mathrm{mol} \mathrm{m} \mathrm{m}^{-2} \mathrm{~s}^{-1}$, respectively, at Moorea and Yonge Reef.

The parameters of the $P-I$ and $G-I$ curves obtained using the first approach (see 'Computation of light response curve parameters') (Fig. 2) were corrupted using a random number generator (Excel 5.0) in order to produce 100 sets of $P-I$ and G-I curves. The corrupted data sets were normally distributed with mean and standard deviation equal, respectively, to the average parameter and asymptotic standard error returned by the curve fitting procedure. 100 daily metabolic budgets were constructed from the $100 P-I$ and $G-I$ curves. Similarly, the 100 sets of $P-I$ and $G$-I parameters derived from the second approach were used to produce 100 daily metabolic budgets.

$P_{\mathrm{g}}, R$ and $G$ were used to estimate the daily air-sea $\mathrm{CO}_{2}$ flux resulting from reef metabolic processes as described by Gattuso et al. (1995).

Statistics. Statistical testing was carried out using JMP 3.0 for Macintosh computers (SAS Institute Inc.). Homoscedasticity was checked prior to the use of analysis of variance (ANOVA). The Welsh procedure (W-ANOVA) was used when the condition of variance homogeneity was not met.

\section{RESULTS}

\section{Community composition and physiographic features}

At Moorea (Tiahura), the number of coral species is close to 80 . The part of the reef flat over which the buoy drifted is composed of 2 benthic communities: a seaward community where corals are dominant and macrophytes are either absent or in moderate abun- dance $(0$ to $8 \%)$ and a second community developed closer to the drainage channel (back reef) with very few corals ( 1 to $2 \%$ ) and abundant macrophytes, principally Turbinaria ornata and Sargassum spp. (12 to $38 \%$ ). Coralline algae were slightly more abundant in the back reef community ( 9 to $21 \%$ ) than in the seaward community (4 to $17 \%$ ).

At Yonge Reef, close to 200 coral species have been recorded overall and the percentage substratum cover by corals can be $>60 \%$ on the upper slopes and on parts of the reef flat. The metabolic experiments were conducted across a single community characterized by dominance of Acropora palifera. Overall, coral cover increased regularly from the algal pavement seaward of the A. palifera zone $(3 \%)$ to the A. grandis community lagoonward $(43 \%)$. Average coral cover in the $A$. palifera (experiment) zone was 30\%. Although no quantitative data are available, the abundance of coralline algae decreased significantly from the outer algal pavement (where it is almost $100 \%$ ) to the $A$. grandis community. The tall phaeophytes Turbinaria and Sargassum were conspicuously absent.

\section{Oceanic parameters}

Seawater parameters measured in the ocean, approximately 1 mile $(1.6 \mathrm{~km})$ of the reef front, are shown in Table 2. Temperature and dissolved oxygen concentration were similar at both sites but $\mathrm{pH}$ and total alkalinity were higher at Moorea than at Yonge Reef, which resulted in a lower oceanic $\mathrm{CO}_{2}$ partial pressure at Moorea than at Yonge Reef (326 vs 349 patm).

\section{Transect experiments: primary productivity and calcification}

The transects were run under similar conditions at both study sites. The average seawater temperature was slightly higher than $27^{\circ} \mathrm{C}$ and the average depths at Moorea and Yonge Reef were, respectively, 1.3 and $1.7 \mathrm{~m}$. Transects were longer at Yonge Reef than at

Table 2. Oceanic parameters at Yonge Reef and Moorea. Mean \pm SE. Sample sizes are shown in parentheses

\begin{tabular}{|lcc|}
\hline & Moorea 1992 & Yonge Reef 1993 \\
\hline Temperature $\left({ }^{\circ} \mathrm{C}\right)$ & $27.1 \pm 0.1(6)$ & $27.2(1)$ \\
$\left.\mathrm{O}_{2}(\mu \mathrm{mol} \mathrm{kg})^{-1}\right)$ & $210 \pm 2(6)$ & $208(1)$ \\
$\mathrm{pH}$ & $8.262 \pm 0.002(6)$ & $8.235(1)$ \\
$\mathrm{TA}\left(\mathrm{meq} \mathrm{kg}{ }^{-1}\right)$ & $2.378 \pm 0.003(7)$ & $2.334 \pm 0.003(3)$ \\
$\mathrm{pCO}_{2}(\mu \mathrm{atm})$ & $326 \pm 2(6)$ & $349(1)$ \\
\hline
\end{tabular}


Moorea ( 463 vs $382 \mathrm{~m}$ ) and were completed in less time ( 0.33 vs $0.71 \mathrm{~h})$ due to higher current velocity. Wind speed never exceeded $11 \mathrm{~m} \mathrm{~s}^{-1}$ and was, on average, $2 \mathrm{~m} \mathrm{~s}^{-1}$ higher at Yonge Reef than at Moorea.

The starting values for transects at Moorea and Yonge Reef were as follows (mean $\pm \mathrm{SE}_{i} \mathrm{n}=12$ at Moorea and $\mathrm{n}=15$ at Yonge Reef): dissolved oxygen, $217 \pm 2$ and 218 $\pm 2 \mu \mathrm{mol} \mathrm{kg}^{-1} ; \mathrm{pH}, 8.277 \pm 0.003$ and $8.241 \pm 0.002$; TA, $2.367 \pm 0.002$ and $2.329 \pm 0.001$ meq $\mathrm{kg}^{-1}$

Seawater temperature increased slightly during transects carried out during the day and decreased slightly at night. The range of temperature variation was -0.1 to $+0.4^{\circ} \mathrm{C}$. Other parameters changed within the following ranges: $\mathrm{O}_{2},-13$ to $+39 \mu \mathrm{mol} \mathrm{kg}^{-1} ; \mathrm{pH}$, -0.019 to $+0.048, \mathrm{TA}_{1}-0.001$ to +0.020 .

\section{Metabolic quotients}

The average respiratory quotient $(R Q)$ was $0.9 \pm 0.2$ at Moorea (mean $\pm \mathrm{SE}_{i} \mathrm{n}=2$ ) and $0.8 \pm 0.1$ at Yonge Reef $(\mathrm{n}=3)$. It was significantly lower than $1(\mathrm{p}=0.04)$ at Yonge Reef. $P Q_{\text {net }}$ was $1 \pm 0.1$ at Moorea $(n=5)$ and $1.1 \pm 0.1$ at Yonge Reef $(n=10)$; it was not significantly different from $1(p>0.25)$. True $P Q$ was not significantly different at Moorea $(1.07 \pm 0.06 ; \mathrm{n}=10)$ or Yonge Reef $(1.08 \pm 0.03 ; n=12)$.

\section{Productivity- and calcification-irradiance curves}

The analysis of propagation of errors for data collected at Yonge Reef revealed that the average standard deviation of net productivity $\left(\mathrm{O}_{2}\right.$ and $\left.\mathrm{CO}_{2}\right)$ and calcification rates expressed as a percentage of the mean were $9 \%$ (6 to $24 \%$ ), $20 \%$ (9 to $41 \%$ ) and $109 \%$ ( 15 to $449 \%$ ), respectively.

The parameter estimates of the light response curves ( $P-I$ and $G-I$ ) obtained from curve-fitting of the original data sets and of the 100 data sets derived from the Monte Carlo simulation differed on average by approximately $2 \%$. The asymptotic standard errors given by the non-linear curve fitting routines correspond to the square root of the diagonal of the covariance matrix and represented therefore the standard deviation of the parameters (Zimmerman et al. 1987). Asymptotic error variances were, on average, 1.4 times higher with the non-linear curve fitting procedure than with the Monte Carlo simulation. We chose to report the asymptotic standard errors in order to enable comparisons with results previously published.

All functions fitted to the experimental productivity-irradiance $(P-I)$ data provided similar values of $r^{2}$, all of them higher than 0.9 (data not shown). The function displaying the lowest range of asymptotic stan-
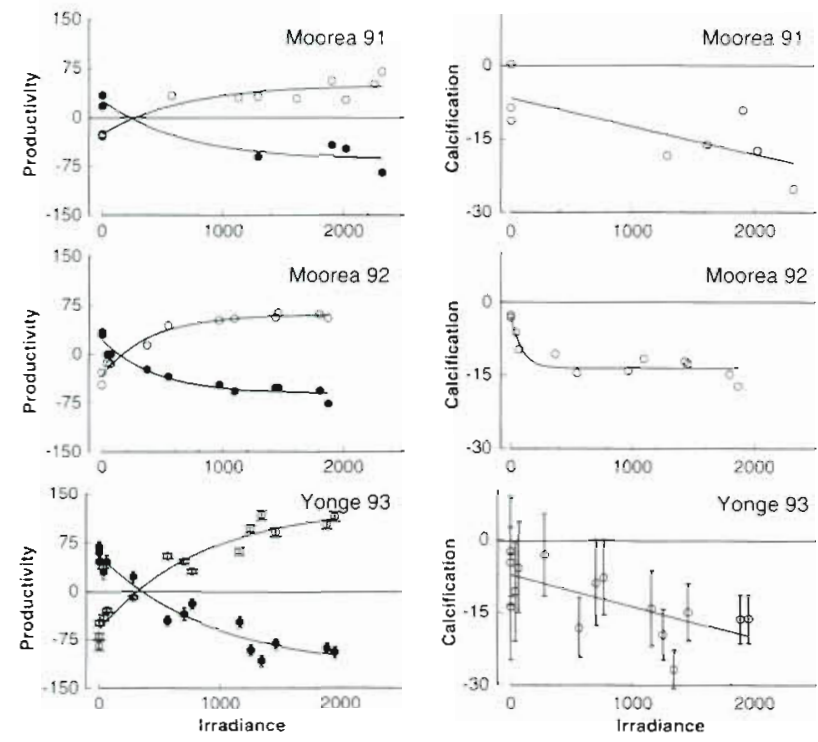

Fig. 3. Community photosynthesis- and calcification-irradiance curves. Net primary productivity in $\mathrm{mmol} \mathrm{O}_{2} \mathrm{~m}^{-2} \mathrm{~h}^{-1}(\mathrm{O})$ or mmol $\mathrm{CO}_{2} \mathrm{~m}^{-2} \mathrm{~h}^{-1}()_{\text {; }}$ calcification in $\mathrm{mmol} \mathrm{CaCO}_{3} \mathrm{~m}^{-2} \mathrm{~h}^{-1}$; incident irradiance in $\mu \mathrm{mol}$ photons $\mathrm{m}^{-2} \mathrm{~h}^{-1}$ Light response curves for Moorea in summer 1991 are from Gattuso et al. (1993). Error bars shown for Yonge Reef were derived by the propagation of error approach (see text) and are $\pm 1 \mathrm{SE}$. Calcification rates are expressed as negative values and rates of dissolution of $\mathrm{CaCO}_{3}$ as positive values

dard error was selected for each site (exponential function at Moorea and hyperbolic tangent function at Yonge Reef). The absolute values of the P-I curve parameters obtained by the $\mathrm{O}_{2}$ and the $\mathrm{CO}_{2}$ techniques were not significantly different, and the light response curves displayed similar shapes (Fig. 3). The maximum gross productivity $\left[p_{\max }\left(\mathrm{CO}_{2}\right)\right]$ was higher at Yonge Reef than at Moorea (158 vs $90 \mathrm{mmol} \mathrm{m} \mathrm{m}^{-2} \mathrm{~s}^{-1}$ ) but the saturation part of the P-I curve was not reached at Yonge Reef (Fig. 3). The rate of dark respiration $\left[r\left(\mathrm{CO}_{2}\right)\right]$ was also higher at Yonge Reef than at Moorea (-53 vs $-31 \mathrm{mmol} \mathrm{m}^{-2} \mathrm{~s}^{-1}$ ) and $I_{k}$ (the incidence at which the inital linear portion of the curve intercepts the saturation plateau) was 3 times higher at Yonge Reef than at Moorea.

There was no net reef dissolution, even at night, at either site. The magnitude of net calcification was similar at Moorea and Yonge Reef but data were noisier at the latter site (Fig 3). An exponential function was fitted to the calcification-irradiance $(G-h)$ curve obtained at Moorea $\left(r^{2}=0.86\right)$ whereas a linear function was used at Yonge Reef $\left(r^{2}=0.45\right)$.

\section{Daily metabolic budgets}

In accordance with earlier procedures (Gattuso et al. 1993), the sign of the daily metabolic parameters 
Table 3. Comparison of daily irradiance $\left\{I_{\mathrm{d}}\right)$ and daily metabolic parameters $\left(\mathrm{CO}_{2}\right.$ technique $\}$ obtained using a daily light curve modelled by a sine function and an average light curve computed from measured light data. $P_{\mathrm{q}}$ : gross primary production; $R: 24 \mathrm{~h}$ respiration; $E$ : excess production; $G$ : net calcification. $P_{g} / R$ : absolute and dimensionless values. Mean $\pm \mathrm{SE}$ obtained from a Monte Carlo simulation

\begin{tabular}{|c|c|c|c|c|c|c|}
\hline & $\left(\mathrm{mol} \mathrm{m}^{-2} \mathrm{~d}^{-1}\right)$ & $P_{\mathrm{g}}$ & $\begin{array}{c}R \\
\text { ol } \mathrm{CO}_{2} \mathrm{~m}^{-2}\end{array}$ & $\left.\mathrm{~d}^{-1}\right)^{E}$ & $P_{\mathrm{g}} / R$ & $\frac{\mathrm{G}}{\left(\mathrm{mmol} \mathrm{CaCO}_{3} \mathrm{~m}^{-2} \mathrm{~d}^{-1}\right)}$ \\
\hline \multicolumn{7}{|l|}{ Moorea } \\
\hline Sine & 49.4 & $-955 \pm 10$ & $730+16$ & $-225 \pm 18$ & $1.38 \pm 0.04$ & $-199 \pm 4$ \\
\hline Average light & 41.3 & $-821 \pm 9$ & $730 \pm 16$ & $-91 \pm 18$ & $1.18 \pm 0.03$ & $-186 \pm 4$ \\
\hline \multicolumn{7}{|l|}{ Yonge Reef } \\
\hline Sine & 72.4 & $-1729 \pm 23$ & $1243 \pm 19$ & $-486 \pm 29$ & $1.42 \pm 0.03$ & $-310 \pm 6$ \\
\hline Average light & 41.9 & $-1279 \pm 21$ & $1243 \pm 19$ & $-36 \pm 28$ & $1.05 \pm 0.02$ & $-253 \pm 5$ \\
\hline
\end{tabular}

Table 4. Observed and simulated daily irradiance $\left(I_{d} ;\right.$ mol photons $\mathrm{m}^{-2} \mathrm{~d}^{-1}$ ) during the least cloudy days that occurred during the field experiments at Moorea and Yonge Reef. Data from Aqaba (Jordan) were collected during a cloud-free day (M. Marchioretti unpubl. data). Overestimation of the observed irradiance is shown in parentheses

\begin{tabular}{|lccc|}
\cline { 2 - 4 } & Moorea & Yonge Reef & Aqaba \\
\hline Date: & $20 \mathrm{Jul} 1992$ & $7 \mathrm{Dec} 1993$ & 19 May 1995 \\
$I_{\mathrm{d}}$ (observed) & 41 & 50 & 54 \\
$I_{\mathrm{d}}$ (civil twilights) & $47(+15 \%)$ & $61(+22 \%)$ & $63(+17 \%)$ \\
$I_{\mathrm{d}}$ (sunrise-sunset) & $44(+7 \%)$ & $58(+16 \%)$ & $59(+9 \%)$ \\
$I_{\mathrm{d}}$ (from sin $\beta$ ) & $44(+7 \%)$ & $57(+14 \%)$ & $57(+6 \%)$ \\
& & & \\
\hline
\end{tabular}

expressed in molar units is shown in Table 3 but absolute values are reported in the text and/or when using weight units. All parameters related to the organic metabolism were computed using net primary productivity measured according to the $\mathrm{CO}_{2}$ technique.

Estimates of the daily metabolic parameters obtained from the original data sets and from the 100 data sets derived from the Monte Carlo simulation differed by less than $3 \%$. Estimates reported in this section are those derived from the latter procedure. Integration of the photosynthesis-irradiance curves provided good consistency between the oxygen and carbon dioxide techniques. The average gross production $\left(P_{\mathrm{g}}\right)$ and daily respiration $(R)$ obtained by both methods differed by less than $15 \%$ and the $P_{g} / R$ ratios were very similar (data not shown). The standard errors of $P_{g}, R$ and $G$, expressed as a percentage of the mean, were typically lower than $2 \%$. The standard error was also relatively low for $P_{\mathrm{g}} / R(<3 \%)$ but comparatively larger for $E$, the excess (= net) production ( 6 to $78 \%$ ).

Daily surface irradiance was $41.3 \pm 0.8 \mathrm{~mol} \mathrm{~m}^{-2} \mathrm{~d}^{-1}$ at Moorea $(n=7)$ and $41.9 \pm 2.4 \mathrm{~mol} \mathrm{~m}^{-2} \mathrm{~d}^{-1}$ at Yonge Reef $(n=9)$. The diel light curve is not adequately modelled by a sine function which overestimates the irradiance by a factor of 1.3 at local solar noon and by a factor of 2 to 1000 during the early morning (05:10 to 09:00 h) and late afternoon (16:30 to 19:09 h) at Yonge Reef. Consequently, the average simulated daily irradiance obtained using a sine model overestimates the measured daily irradiance by 20 to $73 \%$ (Table 4 ). As a result, $P_{\mathrm{g}}$ and $G$ and $P_{\mathrm{g}} / R$ are also overestimated when using a modelled diel light curve. All daily metabolic parameters were therefore computed using measured light data.

$P_{\mathrm{g}}$ and $G$ both increased as a function of daily irradiance $\left(I_{\mathrm{d}}\right)$ but $G$ increased at a slower rate than $P_{\mathrm{q}}$. As a result, $P_{\mathrm{g}} / R$ increased and $G / P_{\mathrm{g}}$ decreased as a function of increasing daily irradiance (Fig. 4).

The metabolism of organic carbon was significantly higher at Yonge Reef than at Moorea ( $t$-test, $p<0.001$ ). $P_{\mathrm{g}}$ and $R$ were approximately $40 \%$ higher at Yonge Reef than at Moorea (1279 vs 821 and 1243 vs $730 \mathrm{mmol} \mathrm{CO} \mathrm{m}^{-2} \mathrm{~d}^{-1}$ ). The average excess production (E) was similar at both sites (W-ANOVA; $p=0.09$ ). It was significantly lower than 0 at Moorea $(p<0.001)$ but was not statistically different from 0 at Yonge Reef $(\mathrm{p}=0.20)$. The $P_{\mathrm{g}} / R$ ratio was significantly higher at

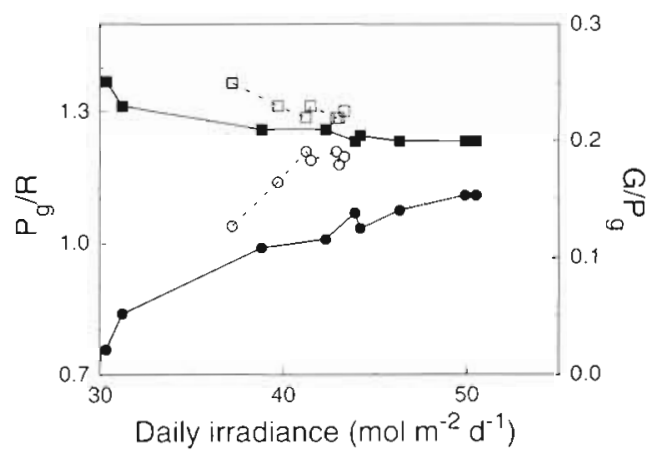

Fig. 4. $P_{\mathrm{g}} / R(0, \bullet)$ and $G / P_{\mathrm{g}}(\square, \square)$ ratios at Moorea (open symbols) and Yonge Reef (solid symbols) as a function of daily irradiance. $P_{\mathrm{g}}$ : daily gross primary production; $R$ : daily respiration; $G$ : daily net calcification 


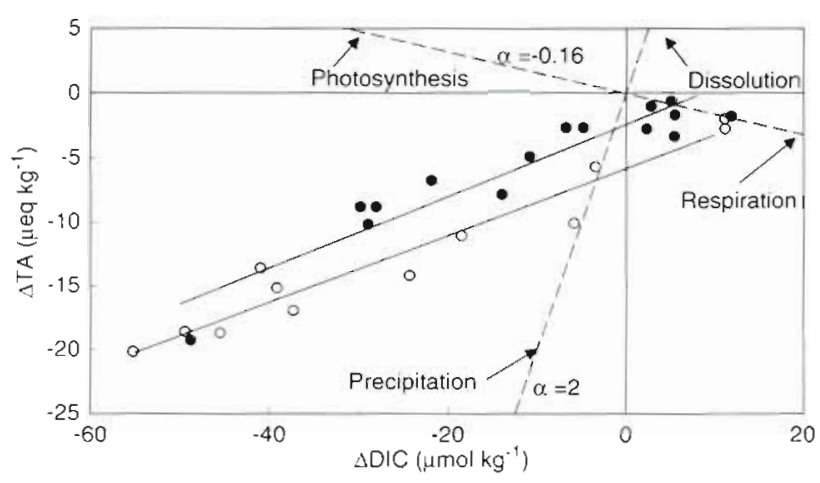

Fig. 5. Changes in total alkalinity ( $\triangle T A$ ) as a function of changes in dissolved inorganic carbon $(\triangle D I C)$ during the transect experiments at Moorea (O) and Yonge Reef ( $\bullet$ ). Functional regression lines are shown with a solid line. Dashed pattern shows the theoretical relationships when photosynthesis-respiration or precipitation/dissolution of calcium carbonate are the sole processes taking place (see text). $\alpha$ : slopes of the theroretical relationships

Moorea than at Yonge Reef (1.18 vs 1.05; W-ANOVA, $\mathrm{p}=0.002)$ and both were significantly higher than $1(t-$ test, $\mathrm{p}<0.01$ ).

The net calcification during the day was 4 times higher than at night at Moorea (150 vs $36 \mathrm{mmol} \mathrm{m}^{-2}$ ) and 2.5 times higher at Yonge Reef (181 vs $72 \mathrm{mmol}$ $\mathrm{m}^{-2}$ ). The average daily calcification was significantly higher at Yonge Reet than at Moorea (253 vs $186 \mathrm{mmol}$ $\left.\mathrm{m}^{-2} \mathrm{~d}^{-1}\right)$.

The changes in TA and DIC were significantly correlated at Moorea and Yonge Reef (Fig. 5). Functional regression was used instead of predictive regression because both variables were subject to experimental error (see Jacques \& Pilson 1980). The regression lines, with $\triangle \mathrm{TA}$ in $\mu \mathrm{eq} \mathrm{kg}^{-1}$ and $\triangle \mathrm{DIC}$ in $\mu \mathrm{mol} \mathrm{kg} \mathrm{kg}^{-1}$, were

Moorea: $\triangle \mathrm{TA}=-5.81+0.27 \Delta \mathrm{DIC}\left(\mathrm{r}^{2}=0.94, \mathrm{n}=12\right)$

Yonge Reef: $\triangle \mathrm{TA}=-3.96+0.28 \Delta \mathrm{DIC}\left(\mathrm{r}^{2}=0.88, \mathrm{n}=15\right)$

Since $1 \mathrm{~mol}$ of $\mathrm{CaCO}_{3}$ is precipitated when TA decreases by 2 equivalents, the contribution of inorganic carbon metabolism on instantaneous changes in DIC were, respectively, 13 and $14 \%$, at Moorea and Yonge Reef

\section{Air-sea $\mathrm{CO}_{2}$ disequilibrium}

The daily air-sea $\mathrm{CO}_{2}$ flux resulting from reef metabolic processes $\left(\mathrm{F}_{\mathrm{CO}_{2}}\right.$ ) was positive (i.e. $\mathrm{CO}_{2}$ evasion) throughout the field experiments and declined as a function of increasing daily irradiance from 114 to $0 \mathrm{mmol} \mathrm{CO} \mathrm{Cm}^{-2} \mathrm{~d}^{-1}$ at Moorea and from 366 to $52 \mathrm{mmol} \mathrm{CO}_{2} \mathrm{~m}^{-2} \mathrm{~d}^{-1}$ at Yonge Reef (Fig. 6). The average $\mathrm{F}_{\mathrm{CO}_{2}}$ during our experiments were $31 \pm 15$ and 182 $\pm 47 \mathrm{mmol} \mathrm{m} \mathrm{m}^{-2} \mathrm{~d}^{-1}$, respectively, at Moorea and Yonge Reef. Both estimates were significantly higher than 0 ( $t$-test, $p<0.04$ ) and their difference was statistically significant ( $W$-ANOVA, $p=0.02$ )

\section{DISCUSSION}

Our results provide an estimate of the uncertainty associated with metabolic parameters as well as information on seasonal and geographic differences of metabolic performances of 2 Pacific reef flats. They also provide, along with a companion paper (Frankignoulle et al. 1996), further evidence that coral reef flats are sources of $\mathrm{CO}_{2}$ for the atmosphere.

Net primary productivity was measured by both the $\mathrm{O}_{2}$ and $\mathrm{CO}_{2}$ techniques and this enabled estimation of the photosynthetic $\left(P Q_{\text {nel }}\right)$ and respiratory quotients $(R Q)$. These quotients are useful to express productivity data measured by the $\mathrm{O}_{2}$ technique in terms of $\mathrm{CO}_{2}$ and are required to estimate calcification when using the $\mathrm{pH}-\mathrm{O}_{2}$ technique (Barnes 1983). Their interrelationship is also important because they are related to the concepts of autotrophy and heterotrophy (Barnes 1983). The average $P Q_{\text {net }}$ at Moorea and Yonge Reef are in good agreement with the data set published by Kinsey (1979) suggesting that $P Q_{n e t}$ is in the range of 1.0 to 1.1 in reef flats dominated by corals and coralline algae. However, we found average $R Q$ s lower than 1 , and the generally assumed relationship, according to which $P Q_{\text {net }}^{-1}=R Q=1$ (see Barnes 1983), was not valid. Barnes (1983) showed that estimates of community metabolism obtained by the $\mathrm{pH}-\mathrm{O}_{2}$ technique were relatively robust to the set of metabolic quotients, but we suggest that care should be exercised when using empirically derived metabolic quotients. All daily metabolic parameters reported in the present paper were computed using the net primary productivity measured according to the $\mathrm{CO}_{2}$ technique.

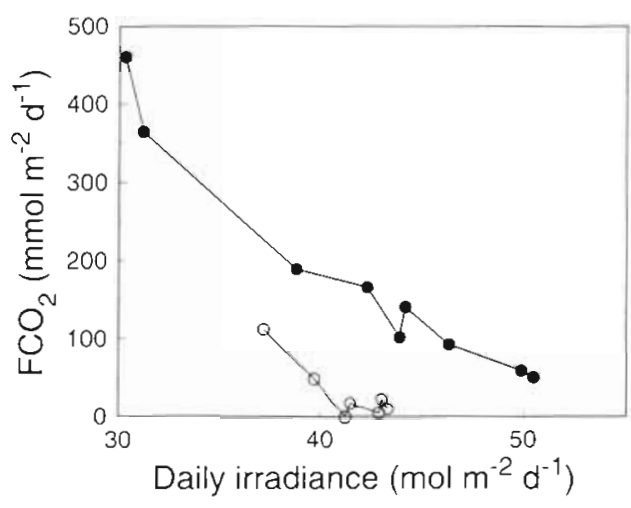

Fig. 6. Estimated air-sea $\mathrm{CO}_{2}$ fluxes at Moorea (O) and Yonge Reef ( as a function of daily irradiance 
In our first approach, to provide confidence intervals for daily metabolic parameters, a Monte Carlo simulation was applied to the rates of net primary production $\left(p_{\text {net }}\right)$ and calcification $(g)$ measured during each transect using their standard errors as derived by taking into account the errors of each variable used to compute the $p_{\text {net }}$ and $g$. The resulting $100 P-I$ and $G-I$ curves were then numerically integrated using a daily light curve. Such a technique is sensitive to the set of errors used, and some of the errors we used are probably underestimated. For example, Dickson \& Riley (1978) reported that DIC computed from pH and total alkalinity is known to within $0.6 \%$ but, since the uncertainty on $\mathrm{pH}$ measurements is higher in the field than in the laboratory, it is likely that the standard error of DIC was higher than $0.6 \%$ in the present study.

In the second approach, the Monte Carlo procedure is applied to the parameters of the $P-I$ and $G-I$ curves, using the standard error or the asymptotic standard error predicted by the curve fitting routine. We suggest, however, that confidence intervals obtained with this technique are relatively conservative since the asymptotic errors variances were 1.4 times higher with the non-linear curve fitting than with the 'propagation of error' approach. The results show that the confidence intervals of the 'primary' daily metabolic parameters and for $P_{\mathrm{g}} / R$ are narrow but that they are comparatively larger for $E$, the excess production.

We found that simulated light data grossly overestimated the average daily irradiance at Moorea and Yonge Reef and, in turn, overestimated community gross production and calcification. Daily metabolic performances of algae (e.g. Zimmerman et al. 1994), symbiotic organisms (e.g. Chalker \& Dunlap 1983) and reef flats (e.g. Barnes \& Devereux 1984, Gattuso et al. 1993) are often computed by numerically integrating photosynthesis-irradiance curves using simulated solar radiation. Such a procedure provides metabolic estimates on a cloudless day and enables comparison of data collected under varying cloud cover. Solar surface radiation is simulated assuming that the daily variation of irradiance follows a sine function between the beginning of the morning civil twilight and the end of evening civil twilight (civil twilight is the interval during which the sun is between the horizon and $6^{\circ}$ below the horizon; Chalker \& Dunlap 1983, Barnes \& Devereux 1984), or during the period when irradiance is different from zero (this study), and by setting the maximum irradiance at noon to a measured value. Other authors (e.g. Zimmerman et al. 1994) have assumed that the daily variation of irradiance follows a sine function between sunrise and sunset

Surface irradiance data collected during the least cloudy days that occurred during measurements of reef community metabolism at Moorea and Yonge Reef are not well described when using the times of civil twilights (Table 4). The simulated data always overestimate the measured irradiance and, as a result, the daily irradiance is overestimated by 15 to $22 \%$. Calculating daylength using the times of sunrise and sunset instead of the times of the civil twilights significantly decreases the simulated daily irradiance which remains nevertheless higher than the measured daily irradiance. The discrepancy between simulated and observed data are partly due to a combination of 2 factors. Firstly, the maximum irradiance required in the modelling function is poorly known. Maximum irradiance data are critical since any error on peak irradiance is carried over the whole daily light curve. In the present study, it was estimated by averaging all peak irradiances measured during the field trips. However, due to ship motion, light reflections and/or focussing effects on the edges of clouds (D. J. Barnes \& B. E. Chalker pers. comm.), some very high values (up to $2470 \mu \mathrm{mol} \mathrm{m} \mathrm{m}^{-2} \mathrm{~s}^{-1}$ ) were recorded, which resulted in unrealistically high maximum irradiances. Secondly, cloudy periods occurred at Yonge Reef and the sine function, as expected, did not properly mimic real light curves and led to an overestimation larger than at Moorea. Measurements took place during a nearly cloudless day at Moorea but simulation still overestimates the observed daily irradiance by $15 \%$. Similar calculations carried out with data collected at Aqaba (Jordan; $29^{\circ} 30^{\prime} \mathrm{N}, 35^{\circ} \mathrm{E} ; \mathrm{M}$. Marchioretti unpubl. data) during an absolutely cloud-free day provide similar results, suggesting that the simulation procedure may not be appropriate.

Kirk (1994) has provided a detailed analysis of the diurnal variation of solar irradiance. Irradiance of a horizontal surface due to direct solar radiation is proportional to the cosine of the solar zenith angle and to the sine of the solar elevation $(\beta)$. Therefore, solar irradiance varies over a $24 \mathrm{~h}$ period in a similar fashion as $\sin \beta$, except that its value is zero at night. The variation of $\sin \beta$ is sinusoidal with respect to time measured within a 24 h cycle (from 00:00 h) but not with respect to daylight hours. The increased atmospheric pathlength early in the morning and late in the afternoon results in an increased attenuation (although partly offset by a greater contribution from skylight) which has the effect of making the diurnal variation of irradiance approximately sinusoidal with respect to daylight hours (Kirk 1994).

Our data show that simulation of daily irradiance using the diurnal variation of $\sin \beta$ provides better estimates, with overestimation down to $6 \%$, of daily irradiance on a cloudless day than the other procedures (Table 4).

The use of simulated irradiance data has the useful advantage of enabling comparison of daily metabolic 
budgets of organisms and communities irrespective of the cloud cover. It has, however, some drawbacks when cloudy passages occur during metabolic measurements. Firstly, it makes the implicit assumption that the relationship between productivity and irradiance observed on cloudy days can be used to predict productivity at high irradiances. Secondly, it can be difficult to estimate the maximum irradiance at local solar noon. Additionally, diumal changes in irradiance are not adequately simulated by a sine curve between the times of sunrise and sunset or the times of the civil twilights. It is suggested that the use of a sine curve with respect to hours from 00:00 h (using the variation of $\sin \beta$ ) or the use of real light data should be preferred.

Community gross primary production and respiration at both study sites ( 9 to $15 \mathrm{~g} \mathrm{C} \mathrm{m}^{-2} \mathrm{~d}^{-1}$ ) are higher than the rates reported by Kinsey $(1983,1985)$ for 'standard' reef flats $\left(P_{\mathrm{g}}=R=7 \pm 1 \mathrm{gC} \mathrm{m}^{-2} \mathrm{~d}^{-1}\right)$ but remain within the range that he reported $(4$ to $19 \mathrm{~g} \mathrm{C}$ $\mathrm{m}^{-2} \mathrm{~d}^{-1}$ ). Net calcification (19 to $25 \mathrm{~g} \mathrm{CaCO}_{3} \mathrm{~m}^{-2} \mathrm{~d}^{-1}$ ) was also higher than Kinsey's 'standard' range $(8$ to $14 \mathrm{~g} \mathrm{CaCO}_{3} \mathrm{~m}^{-2} \mathrm{~d}^{-1}$ ). The latter result could be explained by the relatively high abundance of the major calcifying organisms (corals and calcareous algae).

There was a marked effect of the period of measurement and site on the metabolic performances of the 2 reefs investigated. The barrier reef at Moorea displayed a higher rate of organic production and a lower rate of calcification in winter (this study) compared with measurements carried out during the previous summer (Gattuso et al. 1993). The ratios between the summer and winter values are 0.8 for $P_{g}$ and 1.3 for $G$.

Kinsey (1985) reviewed the effect of seasonality on reef community metabolism; data available at that time showed that, in every reef investigated, the gross primary production, respiration and net calcification were approximately twice as high in summer than in winter. Barnes (1988) subsequently reported similar findings at
Davies Reef (GBR), except for $R$, which was slightly lower in summer than in winter. The seasonality of community metabolism of the Moorea ('Tiahura') barrier reef flat has been studied extensively by Payri (1987). In 1984 and $1985, P_{\mathrm{g}}$ and $R$ were 1.5 times higher in summer than in winter and $G$ was 2.5 times greater. Our observation of a decrease in $G$ between summer 1991 and winter 1992 is therefore consistent with the behaviour of all reefs previously investigated, but the increase in $P_{\mathrm{q}}$ and $R$ from summer to winter is not.

There is some hope that metabolic parameters may be used as an indication of reef health (Buddemeier 1996). The barrier reef flat at Moorea could be a good site to test such a hypothesis since its community metabolism has been investigated on several occasions during the past 15 yr (Table 5). During this time span, the reef was subject to various stresses, such as infestation of the starfish Acanthaster planci (Faure 1989), bleaching (Salvat 1992), cyclone (Delesalle et al. 1993, Harmelin-Vivien 1994) and, possibly, eutrophication (Wolanski et al. 1993), which have led to changes in the benthic communities (Bouchon 1985, Galzin et al. 1993, D. H. Augustin unpubl. data). Overall, $P_{\mathrm{g}}, R$ and $G$ are variable but net calcification seems relatively higher in the more recent measurements (Table 5) Part of the variability is due to the effect of seasonality (see above) but also to different experimental procedures. The early studies (Sournia et al. 1981, Pichon 1985. Payri 1987) used the slack-water technique, whereas the latest ones used the flow respirometry technique. Both approaches relate to spatially different areas: the metabolic parameters obtained by the former technique relate to a limited area of a few square metres, whereas the latter integrates a much greater surface area, typically of the order of several hundred square meters. It is therefore still difficult to correlate the long-term changes in metabolic performances with the health status of the Tiahura Barrier Reef.

Net calcification at Yonge Reef (summer) was higher than at Moorea (winter; 25.3 vs $18.6 \mathrm{~g} \mathrm{CaCO}_{3} \mathrm{~m}^{-2} \mathrm{~d}^{-1}$ ),

Table 5. Published values of community metabolism at Tiahura and Yonge Reef. $P_{q}:$ gross primary production; $R: 24$ h respiration; E: excess production; $G$ net calcification. $P_{9}, R, E: \mathrm{g} \mathrm{C} \mathrm{m}^{-2} \mathrm{~d}^{-1} ; G: \mathrm{g} \mathrm{CaCO}_{3} \mathrm{~m}^{-2} \mathrm{~d}^{-1}: P_{\mathrm{g}} / R$ : absolute and dimensionless values

\begin{tabular}{|c|c|c|c|c|c|}
\hline Source & $P_{g}$ & $R$ & E & $P_{g} / R$ & $G$ \\
\hline \multicolumn{6}{|l|}{ Tiahura } \\
\hline Sournia et al. \{1981\} & 1.6 .4 to 31.4 & 15.6 to 33.6 & -2.2 to 0.8 & 0.9 to 1.0 & 0 to 1.6 \\
\hline Pichon (1985) & 6.2 & 5.2 & 1 & 1.2 & 7.4 \\
\hline Payri (1987) & 3.1 to 13 & 3.4 to 14.3 & -1.8 to 1.2 & 0.7 to 1.1 & -0.7 to 33.0 \\
\hline Le Campion-Alsumard et al. (1993) & - & - & - & - & 0.5 to 5.2 \\
\hline Gattuso et al. (1993) & 7.7 & 7.7 & 0.02 & 1 & 24.3 \\
\hline Present study & 9.9 & 9 & 0.9 & 1.2 & 18.6 \\
\hline \multicolumn{6}{|l|}{ Yonge Reef } \\
\hline Present study & 15.3 & 15 & 0.4 & 1.1 & 25.3 \\
\hline
\end{tabular}


but this may be due to seasonality rather than to geographic or community structure differences since there is nearly no difference in net calcification between Yonge Reef and Moorea in summer $\left(24.3 \mathrm{~g} \mathrm{CaCO}_{3} \mathrm{~m}^{-2}\right.$ $\mathrm{d}^{-1}$ for Moorea in summer; Gattuso et al. 1993). Summer values of $P_{\mathrm{g}}$ and $R$ displayed, however, a 2 -fold difference between Yonge Reef and Moorea which can be explained by the comparatively higher biomass (in particular of primary producers) at the former site.

The contribution of planktonic primary production to the productivity of the Tiahura reef system was low in austral winter ( $B$. Delesalle unpubl. data) and similar to the contribution estimated by Gattuso et al. (1993) in austral summer $(0.04 \mathrm{vs} 0.15 \%)$.

There is a tight coupling between changes in total alkalinity and dissolved inorganic carbon (DIC), and net calcification contributes to ca $14 \%$ of changes in DIC both at Moorea and Yonge Reef. Since net community calcification and production co-vary as a function of irradiance, this contribution should be relatively similar during the day and night. However, due to the small number of nighttime data available $(\leq 3)$ and their relatively high scatter, it is not clear whether this contribution is constant. Frankignoulle et al. (1996) obtained similar results using independent measurements and a different approach. They estimated that the contribution of net calcification to changes in DIC are 27 and $19 \%$ at Moorea and Yonge Reef, respectively. Additionally, their data confirm that this contribution is constant throughout a diel cycle.

These data can be used to estimate the molar ratio of organic to inorganic carbon uptake. Our approach gives a ratio of $6: 1(0.86: 0.14)$ for both sites, and that of Frankignoulle et al. (1996) gives a ratio of $3: 1$ and $4: 1$, respectively, at Moorea and Yonge Reef There are few estimates of such ratios in photosynthetic and calcifying planktonic ecosystems and none in benthic ecosystems. Robertson et al. (1994) reported a ratio of 1:1 in the northeast Atlantic coccolithophorid bloom. As could be expected, this ratio increases (6:1) when the northeast Atlantic phytoplanktonic community becomes depleted in calcifying coccolithophores and dominated by diatoms (Robertson et al. 1994) and is also high in systems displaying weak $\mathrm{CaCO}_{3}$ production, such as the equatorial Pacific (Archer et al. 1996). It can be concluded that the short-term effect of calcium carbonate precipitation on the inorganic carbon system is comparatively lower in coral reef flats than in actively calcifying transient planktonic communities. The long-term effect of calcification by these permanent ecosystems is, however, likely to be significant.

Reef metabolic processes cause shifts in the inorganic carbon system leading to changes in the magnitude and direction of the $\mathrm{pCO}_{2}$ gradient between seawater and the atmosphere. Such disequilibrium drives air-sea $\mathrm{CO}_{2}$ exchange to restore previous initial (oceanic) conditions. The daily air-sea $\mathrm{CO}_{2}$ flux $\left(\mathrm{F}_{\mathrm{CO}_{2}}\right)$ can be estimated from community metabolism data (Lagrangian approach) but continuous irradiance should preferably be used to derive community metabolic data. The decrease of $\mathrm{F}_{\mathrm{CO}_{2}}$ as a function of increasing irradiance results from a combination of 2 factors. Firstly, there is a differential response of productivity and calcification to incident light. At Yonge Reef, where the most important changes in daily irradiance $\left(I_{\mathrm{d}}\right)$ were observed, $P_{\mathrm{g}}$ increased by a factor of 1.4 as a function of increasing $I_{\mathrm{d}}$ while $G$ increased by a factor of 1.1 only. Secondly, the effect of changes in the balance between $P_{\mathrm{y}}$ and $R$ on $\mathrm{FCO}_{2}$ is comparatively larger than the effect of calcification (Gattuso et al. 1995). Consequently, the increase of $\mathrm{CO}_{2}$ uptake by photosynthesis is higher than the increase in $\mathrm{CO}_{2}$ release by calcification. $\mathrm{F}_{\mathrm{CO}_{2}}$ was significantly higher than 0 ; we therefore conclude that both sites were sources of $\mathrm{CO}_{2}$ to the atmosphere at the time of measurement.

The daily air-sea $\mathrm{CO}_{2}$ fluxes were also estimated in a companion study using a different technique based on a Eulerian approach during 3 diel cycles (Frankignoulle et al. 1996). The direction of the fluxes obtained by both techniques are in agreement $\left(\mathrm{CO}_{2}\right.$ evasion) but there is a discrepancy in their magnitude. Our estimates of $F_{\mathrm{CO}_{2}}$ are higher than those reported by Frankignoulle et al. (1996) by 1 to 2 orders of magnitude: 31 versus $1.8 \mathrm{mmol} \mathrm{m}^{-2} \mathrm{~d}^{-1}$ at Moorea and 182 versus $5.1 \mathrm{mmol} \mathrm{m}^{-2} \mathrm{~d}^{-1}$ at Yonge Reef. Several considerations could explain such a large difference

Firstly, both techniques involve a number of assumptions which are likely to result in some uncertainty of the estimates. For example, the Eulerian approach assumes that (1) there is no change in oceanic $\mathrm{pCO}_{2}$ during and between the diel cycles and (2) that the daily water flow is similar for the 3 diel cycles. Secondly, the 2 studies do not refer to the same communities (Lagrangian vs Eulerian techniques) and do not encompass the same reef area: the zone located between the ocean and the starting point of the transects is not taken into account by the Lagrangian approach, whereas it is included in the estimate based on the Eulerian technique. It is therefore difficult at this stage to estimate precisely the magnitude of the $\mathrm{CO}_{2}$ evasion. Both techniques, however, show that the $\mathrm{CO}_{2}$ release is higher at Yonge Reef than at Moorea. The community metabolism data suggest that this is due to a higher uptake of $\mathrm{CO}_{2}$ by net photosynthesis and a lower release of $\mathrm{CO}_{2}$ by net calcification at Moorea.

Gattuso et al. (1993) showed that the reef flat at Moorea was a source of $\mathrm{CO}_{2}$ to the atmosphere during austral summer 1991 using direct measurements of 


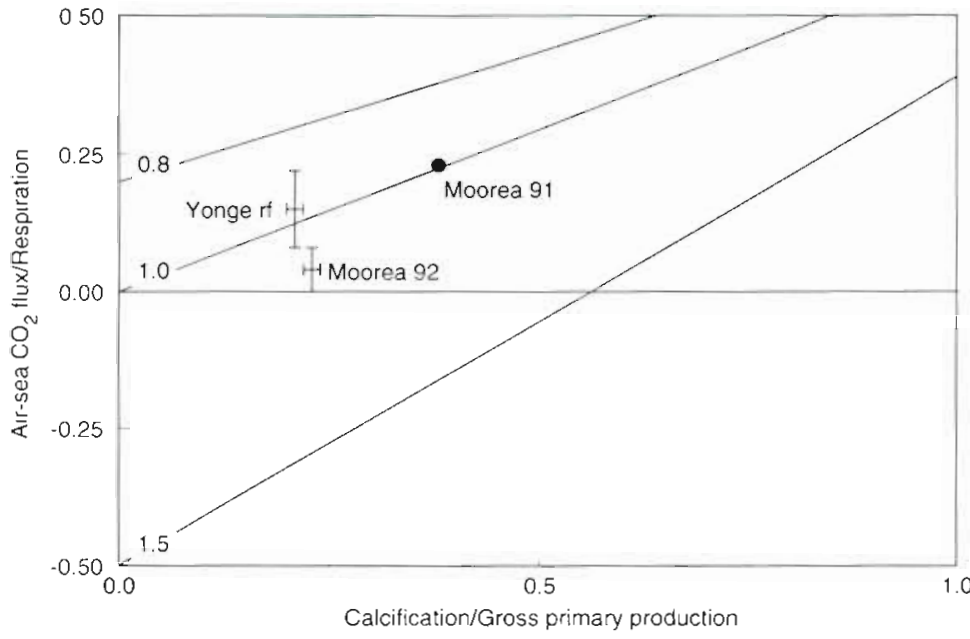

Fig. 7. Estimates of the ratio of air-sea $\mathrm{CO}_{2}$ flux versus community respiration $\left(F_{\mathrm{CO}_{2}} / R\right)$ as a function of $G / P_{\mathrm{g}}$. Data for Moorea 1991 are from Gattuso et al. (1993). Error bars are $95 \%$ confidence limits. Solid lines indicate the model output for the following $P_{\mathrm{g}} / R$ ratıos: $0.8,1.0$ and 1.5 (see Gattuso et al. 1995)

air-sea $\mathrm{CO}_{2}$ fluxes. This conclusion was subsequently confirmed by a model using community metabolism data (Gattuso et al. 1995; Fig. 7) which also suggested that an average coral reef flat was a source of $\mathrm{CO}_{2}$. The present results confirm and extend our previous conclusion on a temporal scale, using wintertime measurements at Moorea, and on a spatial scale on a reef subject to little human impact (Yonge Reef). It also provides evidence that the estimations of air-sea $\mathrm{CO}_{2}$ fluxes are statistically robust since their confidence intervals do not include $F_{\mathrm{CO}_{2}} / R=0$ (Fig. 7). As already pointed out (Gattuso et al. 1995, 1996, Smith 1995), this conclusion does not rule out the possibility that some reefs, or some physiographic zones within a coral reef, display a different role with respect to atmospheric $\mathrm{CO}_{2}$. For example, Barnes \& Lazar (1993) measured the metabolic performance of a high latitude reef patch of the Gulf of Aqaba using techniques similar to ours. They reported daily metabolic parameters $\left(P_{\mathrm{g}}=\right.$ $384 \mathrm{mmol} \mathrm{m} \mathrm{m}^{-2} \mathrm{~d}^{-1}: R=240 \mathrm{mmol} \mathrm{m} \mathrm{m}^{-2} \mathrm{~d}^{-1}$ and $G=$ $163 \mathrm{mmol} \mathrm{m}^{-2} \mathrm{~d}^{-1}$ ) suggesting that this site was a sink for atmospheric $\mathrm{CO}_{2}$ in March $1990\left(F_{\mathrm{CO}_{2}}=-46 \mathrm{mmol}\right.$ $\left.\mathrm{m}^{-2} \mathrm{~d}^{-1}\right)$, probably as a result of an extensive epilithic algal community. The strong relationship between daily irradiance and $\mathrm{FCO}_{2}$ suggests that Moorea and Yonge Reef might display a transient sink-like behaviour when they receive full solar irradiance. This conclusion would only be valid if the light response curves under such conditions are similar to those measured under sub-optimal light conditions and if no saturation phase or photoinhibition occur. This could only be demonstrated through long-term (at least 1 yr) measurements of community metabolism.
Acknowledgements. Assistance in the field was provided by J. Algret, I. Bourge, Y. Chancerelle, E Coutures and A. Salih, as well as by the Master and crew of the RV 'Lady Basten' Thanks are due to C. Bussi for data processing, J. Clavier and F Ibanez for helpful discussion on Monte Carlo simulations, and F. Teaniniuraitemoand for help with positioning the stations at Moorea, as well as the workshop and analytical services staffs of the Australian Institute of Marine Science for helpful assistance. We also thank J. T $O$. Kirk for reviewing an early note on the simulation of solar radiation, M. Marchioretti for providing irradiance data from Aqaba and $M$. Devereux for his help in gathering data from the Nautical Almanac. D. Barnes, B. Chalker, S. V Smith and an anonymous referee provided helpful comments on an earlier draft of the manuscript. This work was supported by grants from Centre National de la Recherche Scientifique (Sciences de la Vie-INSU), Centre Scientifique de Monaco, Australian Institute of Marine Science, Council of Europe, Société Nationale Elf-Aquitaine, Programme National Récifs Coralliens (PNRCO), Australian Department of Industry and Technology and Commerce and FNRS (Belgium), with which M.F. is a research associate. This is a contribution of PNRCO.

\section{LITERATURE CITED}

Archer DE, Takahashi T, Sutherland S, Goddard J, Chipman D. Rodgers K, Ogura H (1996) Daily, seasonal, and interannual variability of sea surface carbon and nutrient concentration in the Equatorial Pacific Ocean. Deep Sea Res $43: 779-808$

Barnes DJ (1983) Profiling coral reef productivity and calcification using $\mathrm{pH}$ and oxygen electrodes. J Exp Mar Biol Ecol 66:149-161

Barnes DJ (1988) Seasonality in community productivity and calcification at Davies Reef, Central Great Barrier Reef Proc 6th Int Symp Coral Reef 2:521-527

Barnes DJ, Devereux MJ (1984) Productivity and calcification on a coral reef a survey using $\mathrm{pH}$ and oxygen electrode techniques. J Exp Mar Biol Ecol 79:213-231

Barnes DJ, Lazar B (1993) Metabolic performance of a shallow reef patch near Eilat on the Red Sea. J Exp Mar Biol Ecol 174:1-13

Bates RG (1982) pH measurements in the marine environment. Pure Appl Chem 54:229-232

Bouchon C (1985) Quantitative studies of scleractinian communities of Tiahura reef (Moorea, French Polynesia). Proc 5th Int Coral Reef Congr 6:279-284

Brown CW, Yoder JA (1994) Coccolithophorid blooms in the global ocean. J Geophys Res 99:7467-7482

Buddemeier RW (1996) Coral reefs and carbon dioxide. Science 271:1298-1299

Chalker BE, Dunlap WC (1983) Primary production and photoadaptation by corals on the Great Barrier Reef. Proc Inaugural Great Barrier Reef Conf, p 293-298

Chisholm JRM, Collingwood JC, Gill EF (1990) A novel in situ respirometer for investigating photosynthesis and calcification in crustose coralline algae. J Exp Mar Biol Ecol 141:15-29

Delesalle B, Pichon M, Frankignoulle M. Gattuso JP (1993) Effects of a cyclone on coral reef phytoplankton biomass, primary production and composition (Moorea Island, French Polynesia). J Plankton Res 15:1413-1423 
Dickson AG (1993) pH buffers for seawater media based on the total hydrogen ion concentration scale. Deep Sea Res 40:107-118

Dickson AG, Riley JP (1978) The effect of analytical error on the evaluation of the components of the aquatic carbondioxide system. Mar Chem 6:77-85

Faure G (1989) Degradation of coral reefs at Moorea Island (French Polynesia) by Acanthaster planci. J Coastal Res 5 $295-305$

Frankignoulle $M$, Gattuso JP, Biondo R, Bourge I, CopinMontégut G, Pichon M (1996) Carbon fluxes in coral reefs. 1I. Eulerian study of inorganic carbon dynamics and moasurement of air-sea $\mathrm{CO}_{2}$ exchanges. Mar Ecol Prog Ser 145:123-132

Galzin R, Marfin JP, Salvat B (1993) Long term coral reef monitoring program: heterogeneity of the Tiahura barrier reef (Moorea, French Polynesia). Galaxea 11:73-91

Galzin R, Pointier JP (1985) Moorea Island, Society Archipelago. Proc 5th Int Coral Reef Congr 1:73-102

Gans P (1992) Data fitting in the chemical sciences by the method of least squares. John Wiley, Chichester

Gattuso JP, Frankignoulle M, Smith SV, Ware JR, Wollast R (1996) Coral reefs and carbon dioxide. Science 27 1:1298

Gattuso JP, Jaubert J (1988) Computation of metabolic quotients in plant-animal symbiotic units. J Theor Biol 130 $205-212$

Gattuso JP, Pichon M, Delesalle B, Frankignoulle M (1993) Community metabolism and air-sea $\mathrm{CO}_{2}$ fluxes in a coral reef ecosystem (Moorea, French Polynesia). Mar Ecol Prog Ser 96:259-267

Gattuso JP, Pichon M. Frankıgnoulle M (1995) Biological control of air-sea $\mathrm{CO}_{2}$ fluxes: effect of photosynthetic and calcifying marine organisms and ecosystems. Mar Ecol Prog Ser 129:307-312

Harmelin-Vivien ML (1994) The effect of storms and cyclones on coral reefs: a review. J Coastal Res (Special Issue) 12 $211-231$

Hatcher BG (1988) Coral reef primary productivity: a beggar's banquet. TREE 3:106-111

Holligan PM, Fernández E, Aiken J, Balch WM, Boyd P, Burkill PH, Finch M, Groom SB, Malin G, Muller K, Purdie DA, Robinson C. Trees CC, Turner SM, van der Wal P (1993) A biogeochemical study of the coccolithophore, Emiliania huxleyı in the North Atlantic. Global Biogeochem Cycles 7:879-900

Jacques TG, Pilson MEQ (1980) Experimental ecology of the temperate scleractunian coral Astangia danae. I. Partition of respiration, phtosynthesis and calcification between host and symbionts. Mar Biol 60:167-178

Kayanne H, Suzuki A, Saito H (1995) Diurnal changes in the partial pressure of carbon dioxide in coral reef water. Science 269:214-216

Kinsey DW (1979) Carbon turnover and accumulation by coral reefs. PhD dissertation, University of Hawaii, Honolulu

Kinsey DW (1983) Standards of performance in coral reef primary production and turnover In: Barnes DJ (ed) Perspectives on coral reefs. Australian lnstitute of Marine Science, Townsville, p 209-220

Kinsey DW (1985) Metabolism, calcification and carbon production. 1. System level studies. Proc 5th Int Coral Reefs Congr 4:505-526

Kinsey DW (1988) Coral reef system response to some natural and anthropogenic stresses. Galaxea $7: 113-128$

Kirk JTO (1994) Light and photosynthesis in aquatic ecosystems. Cambridge University Press, Cambridge

Kraines SB, Suzuki Y, Yamada K, Komiyama H (in press)
Separating biological and physical changes in dissolved oxygen concentration in a coral reef. Limnol Oceanogr

Le Campion-Alsumard T, Romano JC, Peyrot-Clausade M. Le Campion J, Paul R (1993) Influence of some coral reef communities on the calcium carbonate budget of Tiahura reef (Moorea, French Polynesia). Mar Biol 115:685-693

Loya $Y$ (1972) Community structure and species diversity of hermatypic corals at Eilat, Red Sea. Mar Biol 13:100-123

Marsh JA Jr, Smith SV (1978) Productivity measurements of coral reefs in flowing water In: Stoddart DR, Johannes RE (eds) Coral reefs research methods. UNESCO, Paris, p 361-378

Millero FJ, Poisson A (1981) International one-atmosphere equation of state of seawater. Deep Sea Res 28:625-629

Payri CE (1987) Variabilité spatiale et temporelle de la communauté des macrophytes des récifs coralliens de Moorea (Polynésie française). Contribution des algues au métabolisme du carbone de l'écosystème récifal. Thèse de Doctorat d'Etat, Université des Sciences et Techniques du Languedoc, Montpellier

Pichon M (1985) Organic production and calcification in some coral reefs of French Polynesia. Proc 5th Int Coral Reef Congr 6:173-177

Pichon M, Morrissey J (1981) Benthic zonation and community structure of South Island Reef, Lizard Island (Great Barrier Reef). Bull Mar Sci 3:581-593

Robertson JE, Robinson C, Turner DR, Holligan P, Watson AJ Boyd P. Fernández E, Finch M (1994) The impact of a coccolithophore bloom on oceanic carbon uptake in the northeast Atlantic during summer 1991. Deep Sea Res 41 $297-314$

Salvat B (1992) Blanchissement et mortalité des madrépo. raires sur les récifs de Moorea (1les de la Société). C R Acad Sci Parıs Ser III 314:105-111

Smith SV (1978a) Coral-reef area and the contributions of reefs to processes and resources of the world's oceans. Nature 273:225-226

Smith SV (1978b) Alkalinity depletion to estimate the calcification of coral reefs in flowing waters. In: Stoddard DR Johannes RE (eds) Coral reefs: research methods. UNESCO, Paris, p 397-404

Smith SV (1995) Reflections on the measurement and significance of carbon metabolism on coral reefs. Kansas Geological Survey, Open-File Report 95-56a, Lawrence, p 1-18

Smith SV, Key GS (1975) Carbon dioxide and metabolism in marine environments. Limnol Oceanogr 20:493-495

Sournia A. Delesalle B, Ricard M (1981) Premiers bilans de production organique et de calcification d'un récif barrière de la Polynésie Française. Oceanol Acta 4:423-431

Ware JR, Smith SV, Reaka-Kudia ML (1992) Coral reets: sources or sinks of atmospheric $\mathrm{CO}_{2}$ ? Coral Reefs 11 $127-130$

Wolanski E, Delesalle B, Dufour V, Aubanel A (1993) Modeling the fate of pollutants in the Tiahura lagoon, Moorea, French Polynesia. Proc 11th Australasian Conf Coastal Ocean Engineering, p 583-589

Yamamuro M, Kayanne H, Minagawa M (1995) Carbon and nitrogen stables isotopes of primary producers in coral reef ecosystems. Limnol Oceanogr 40:617-621

Zimmerman RC, Cabello-Pasini A, Alberte RS (1994) Modeling daily production of aquatic macrophytes from irradlance measurements: a comparative analysis. Mar Ecol Prog Ser 114:185-196

Zimmerman RC, SooHoo JB, Kremer JN, D'Argenio DZ (1987) Evaluation of variance approximation techniques for non-linear photosynthesis-irradiance models. Mar Biol 95:209-215

Manuscript first received: December 15, 1995

Revised version accepted: October 2, 1996 